\title{
Avaliação da qualidade da água de uma bacia hidrográfica urbana: estudo de caso bacia do rio Pinhalzinho II, Umuarama - PR
}

\author{
Evaluation of water quality of an urban watershed: case study about watershed \\ Pinhalzinho II river, Umuarama - PR
}

\author{
Natália Silva Daneluzzi ${ }^{1]}$ \\ Vanessa Daneluz Gonçalves²(*) \\ Regina Pinheiro de Freitas ${ }^{3}$
}

\section{Resumo}

A bacia hidrográfica do rio Pinhalzinho II possui distintos tipos de uso e ocupação do solo. O uso urbano da cidade de Umuarama está situado na região de importantes nascentes. Diante do rápido desenvolvimento do município e da falta de informações sobre a qualidade da água na região, o levantamento de aspectos visuais e a estimativa dos parâmetros de qualidade da água foram realizados neste trabalho, sendo eles: coliformes totais e termotolerantes, temperatura, condutividade elétrica, $\mathrm{pH}$, turbidez, OD, DBO, DQO, sólidos totais, fixos e voláteis. Este trabalho também teve como objetivo, avaliar a conformidade legal dos parâmetros de qualidade da água mensurados, quanto à legislação vigente e recomendações técnicas. A avaliação dos resultados permitiu identificar no manancial: trechos erodidos; cor aparente variável de marrom a cinza; 40\%:53,3\%:80\%:100\%, respectivamente, dos valores de DBO, turbidez, OD e pH em conformidade legal com a classe II de enquadramento; além de contaminação por coliformes termotolerantes; condutividade elétrica elevada; e DQO de até 77,33 $\mathrm{mgL}^{-1}$. As correlações entre OD e condutividade ( $\left.\mathrm{r}=-0,73\right)$; DBO e OD $(\mathrm{r}=-0,92)$; e DBO e condutividade $(r=0,80)$, sugerem estágio avançado de mineralização da matéria orgânica, em que, à medida que a $\mathrm{DBO}$ é exercida, há um consumo de $\mathrm{OD}$ e um aumento de condutividade. A correlação entre sólidos totais e turbidez $(r=0,94)$ sugere o predomínio dos sólidos na fração particulada. A sub-bacia avaliada apresentou indícios de poluição da água devido à urbanização, à elevada erodibilidade das margens diante da falta de vegetação e ao tipo de solo da região, oriundo dos arenitos de Formação Caiuá, que promovem assoreamento do canal.

Palavras-chave: Gestão de recursos hídricos; Uso do solo; Formação Caiuá.

1 Engenheira Ambiental; Universidade Estadual de Maringá, UEM, Brasil; ; E-mail: nat_daneluzzi@hotmail.com

2 Me.; Engenharia de Recursos Hídricos e Ambiental; Universidade Federal do Paraná, UFPR, Brasil; Professora Assistente da Universidade Estadual de Maringá, leciona nos cursos de Engenharia Ambiental e Tecnologia em Meio Ambiente; Endereço: Universidade Estadual de Maringá, Centro de Tecnologia. Av. Ângelo Moreira da Fonseca, Zona VII. CEP: 87506370 - Umuarama, PR - Brasil; E-mail: van_dg@msn.com $\left(^{*}\right)$ Autor para correspondências

3 Bióloga; Universidade Paranaense, UNIPAR, Brasil; Técnica em laboratório da Universidade Estadual de Maringá; Endereço: Universidade Estadual de Maringá, Centro de Tecnologia, Departamento de Engenharia Química. Rod. Pr 489, 1400, Saída p/ Xambrê. CEP: 87508-210 - Umuarama, PR - Brasil; E-mail: rpfreitas@uem.br

\begin{tabular}{llllll}
\hline Ambiência & Guarapuava (PR) & v.14n.3 & p.678-698 & Set/Dez 2018 & ISSN $1808-0251$
\end{tabular}




\section{Abstract}

The Pinhalzinho II watershed has different types of use and occupation. The urban use corresponding the Umuarama city is located in the region of springs. The rapid development of the city and the scarce information on water quality in the region, motivated this work to make an estimation of visual aspects and the regulation of parameters of water quality, such as: total and thermotolerant coliforms, temperature, electrical conductivity, $\mathrm{pH}$, turbidity, $\mathrm{DO}, \mathrm{BOD}, \mathrm{COD}$, solids fixed and volatile. the water quality parameters measured were evaluated according to current legislation and technical recommendations. The evaluation of the results allowed to identify: eroded sections; apparent color variable from brown to gray; $40 \%: 53.3 \%: 80 \%: 100 \%$, respectively, of the $\mathrm{BOD}$, turbidity, $\mathrm{DO}$ and $\mathrm{pH}$ values in accordance with class 2 of the framing; contamination by thermotolerant coliforms; high electrical conductivity; and COD up to $77.33 \mathrm{mgL}^{-1}$. As correlations between DO and conductivity $(\mathrm{r}=-0.73)$; BOD and DO $(r=-0.92)$; and BOD and conductivity $(r=0.80)$, suggest an advanced stage of organic matter mineralization, in which, as the BOD is exerted, there is an DO consumption and an increase in conductivity. The correlation between total solids and turbidity ( $\mathrm{r}$ $=0.94)$ suggests the predominance of solids in the particulate fraction. The evaluated subbasin showed signs of water pollution due to urbanization, the high erodibility of the margins due to the lack of vegetation and the type of soil of the region, originating from the Caiuá Formation sandstones, which promote sedimentation of the river.

Key words: water resources management; use of the soil; Caiuá Formation.

\section{Introdução}

O Brasil possui, em geral, disponibilidade hídrica em quantidade suficiente para as diversas atividades, porém, a falta de saneamento e o lançamento de efluentes, tanto domésticos quanto industriais nos corpos d'água, resultam na degradação da qualidade desses corpos hídricos, fato que promove um quadro contraditório de escassez (SETTI et al., 2001; FARAGE, 2009). O uso e ocupação do solo pela urbanização têm contribuído para a degradação da qualidade hídrica (PORTO; PORTO, 2008; WILKINS et al., 2015), devido ao lançamento de efluentes, a disposição inadequada de resíduos e à drenagem urbana (CALIJURI et al., 2012) impulsionada pela elevada impermeabilização do solo, com consequente redução da capacidade de infiltração e aumento do escoamento superficial (CHU et al., 2013).

Assim como na maioria das cidades brasileiras, Umuarama-PR sofreu um rápido e desequilibrado crescimento urbano e, com isso, modificações e interferências no ambiente ocorreram, de modo a impactar diretamente o uso do solo e, consequentemente da água, trazendo danos ambientais inevitáveis, além de questões econômicas que afetam todos os setores produtivos (VILLA, 2011; VILLA, 2011a). O município supracitado, situado no noroeste do estado do Paraná, concentra uma população de 100.676 habitantes sob uma área de $1.232,767$ km² (IBGE, 2010).

A região encontra-se no interflúvio das bacias hidrográficas do Piquiri, do Ivaí e a do Paraná II, e possui uso e ocupação do solo diversificado entre pecuária, agricultura, urbanismo e florestas. Esta diversidade ocupacional, em especial a urbana, promove impactos ambientais 
negativos distintos à qualidade dos recursos hídricos. Estudos anteriores, sugerem poluição nas nascentes do Rio Mimosa situado na área central da cidade, mais especificadamente no interior do Parque dos Xetás (RONQUIN, 2010), e no Lago Municipal Aratimbó (TAKEDA; MENDES, MARIN, 2011; CAETANO; MARTINS; MERLINI, 2011), local bastante frequentado pelos umuaramenses.

A qualidade da água é um reflexo dos muitos processos que ocorrem na bacia de contribuição; e pensando nisso não devem ser analisadas apenas características físicas, químicas e biológicas e sim o funcionamento do ecossistema em geral. Distintos estudos têm sido desenvolvidos com o propósito de diagnosticar a qualidade dos rios (IAP, 2005; KNAPIK, 2009; HESPANHOL, 2009; FARAGE,2009; VILLA, 2010) para, assim, sugerir mecanismos de gestão desses ambientes (ARAÚJO; MELO,2000; CALIJURI et al.,2012) e identificar a influência do desenvolvimento urbano nos ecossistemas naturais (CHU et al., 2013; WILKINS et al., 2015).

Nesse contexto, diante da influência exercida pelo uso e ocupação do solo na qualidade dos rios e a carência de informações de qualidade da água na região proposta de estudo, este trabalho teve por objetivo fazer um diagnóstico da qualidade da água do rio Pinhalzinho II sob influência da bacia de contribuição urbana, por meio de uma avaliação visual e da mensuração de parâmetros de coliformes totais e fecais, temperatura, condutividade elétrica, $\mathrm{pH}$, turbidez, oxigênio dissolvido, Demanda Bioquímica de Oxigênio, Demanda Química de Oxigênio, sólidos totais fixos e voláteis.

\section{Material e métodos}

\section{Bacia hidrográfica do rio Pinhalzinho II}

A área de estudo em questão é a sub-bacia hidrográfica do rio Pinhalzinho II, em seu trecho situado na região urbanizada que compreende a cidade de Umuarama-PR. O córrego Pinhalzinho II apresenta regime hídrico perene e é afluente do rio Goioerê que, por sua vez, é tributário da margem direita do rio Piquiri, o qual faz parte do complexo hidrográfico do rio Paraná (FRANÇA JÚNIOR, 2010). De acordo com a Portaria SUREHMA n 17/1991, os cursos d'água pertencentes à bacia do Piquiri estão enquadrados na classe II (PARANÁ, 1991), disposta na Resolução CONAMA n 357/2005 (BRASIL, 2005).

A sub-bacia do córrego Pinhalzinho II possui como geologia predominante rochas sedimentares de Formação Caiuá, com textura de arenosa a média, baixo teor de argila e matéria orgânica, e elevado teor de areia variável entre $85 \%$ e $90 \%$, além de baixo nível de elementos como fósforo, potássio, cálcio e magnésio (FONSECA; CZUY, 2005). Salienta-se que a sub-bacia em estudo pode conter contribuições pontuais e difusas de carga orgânica, por compreender uma área de drenagem com usos urbano, industrial e agropecuário.

\section{Pontos amostrais e coletas}

Para o diagnóstico da qualidade hídrica do rio Pinhalzinho II, foram monitorados 5 pontos amostrais, dos quais três deles pertencem a afluentes do rio Pinhalzinho II (P1, P2 e P3) e dois deles estão no próprio rio principal ( $\mathrm{P} 4$ e $\mathrm{P} 5)$. Optou-se por amostrar pontos afluentes ao rio 
principal com o propósito de avaliar a qualidade da água sob influência de regiões específicas da área urbana. O P1 está localizado em uma região antiga da cidade, com ocorrência de alagamentos e processos de erosão do solo. O P2 possui, a sua montante, as nascentes do rio Mimosa, área do Parque dos Xetás. De forma semelhante, o P3 possui, a sua montante, o Lago Aratimbó, uma área de lazer bastante frequentada e urbanizada. Quanto aos locais de amostragem no rio principal, estes foram escolhidos por se tratar de uma região industrial e de pastagens (P4 e P5), além de P5 localizado no limite da sub-bacia em estudo. A Tabela 1 contém informações de localização geográfica e altitude, e a Figura 1 apresenta a delimitação da sub-bacia em estudo e os locais de amostragem.

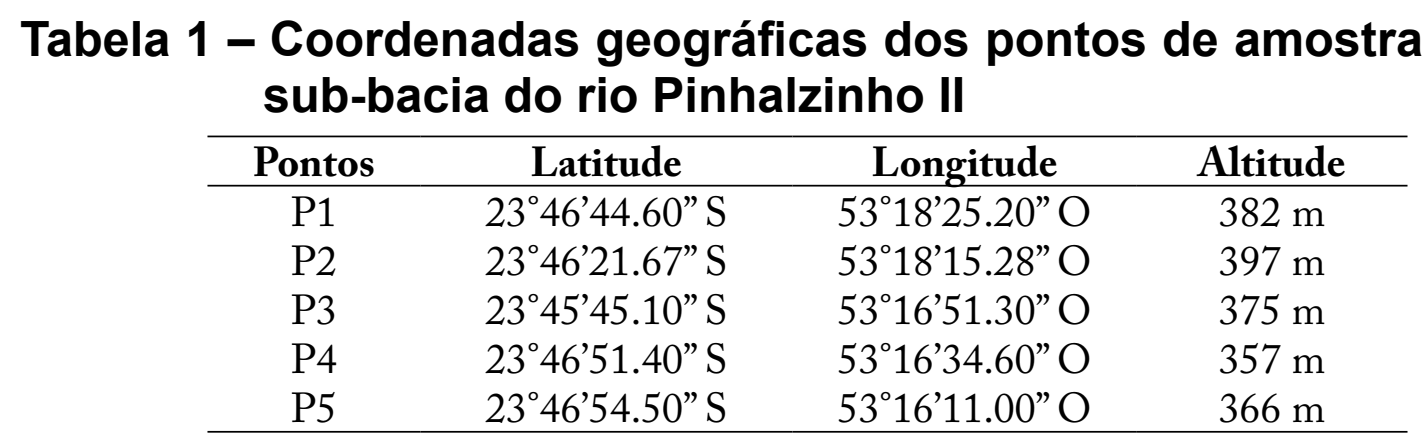

Os autores (2016).

\section{Figura 1 - Delimitação da sub-bacia hidrográfica do rio Pinhalzinho II e localização dos pontos amostrais}

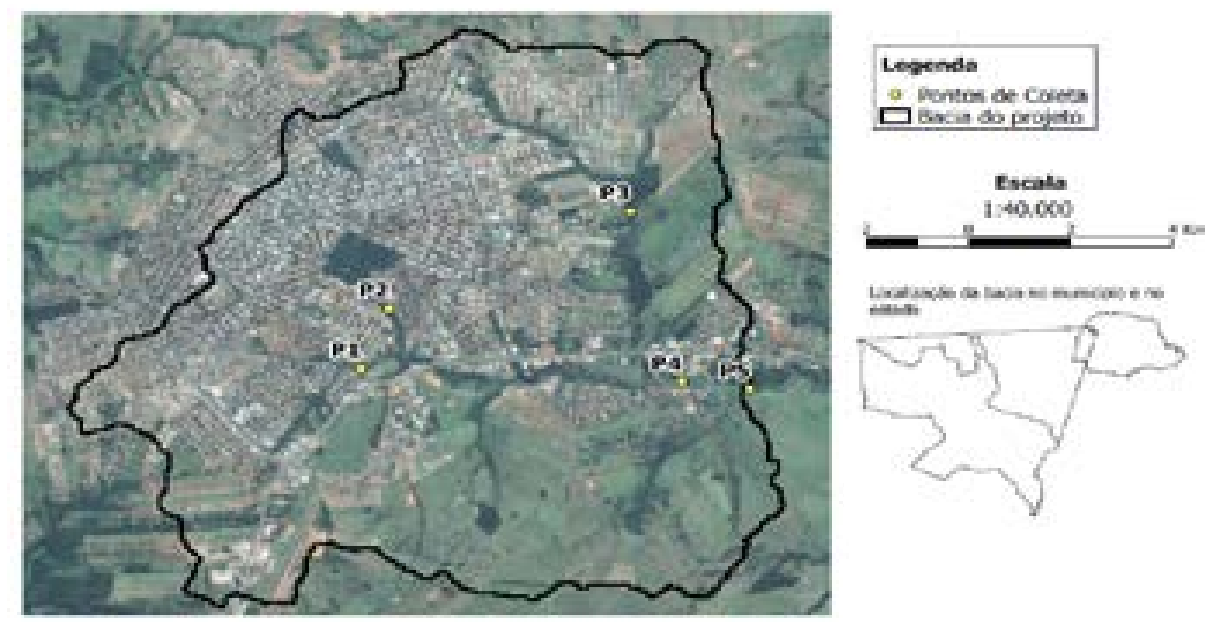

Fonte: Adaptado de Google Earth (2013).

As amostras de água foram coletadas, no período de janeiro a agosto de 2015 , segundo instruções contidas na NBR n ${ }^{\circ} 9.898$ (ABNT,1987). Foram feitas três amostragens que incluíram as estações de verão e inverno, considerando que as campanhas ocorreram nos dias 20/01; 24/07 e $07 / 08$, sendo o horário das coletas entre $10 \mathrm{~h}$ e $15 \mathrm{~h}$. Adicionalmente, foram feitos registros fotográficos do local e anotações quanto à preservação das margens, processos de erosão e assoreamento, presença de resíduos sólidos e cor aparente da água. 


\section{Parâmetros de monitoramento}

Os procedimentos de análise adotados para a obtenção dos parâmetros de qualidade da água seguiram diferentes metodologias conforme apresentado na Tabela 2.

\section{Tabela 2 - Parâmetros monitorados e suas respectivas metodologias de análise ou modelo do equipamento utilizado}

\begin{tabular}{lcc}
\hline \multicolumn{1}{c}{ Parâmetros } & Método & Referência \\
\hline Coliformes Totais e Termotolerantes & Tubos Múltiplos (NMP/100 mL) & BRASIL (2009) \\
\hline Temperatura & TECNOPON/ mCa 150 P & \\
Condutividade Elétrica, CE & TECNOPON/ mCa 150 P & - \\
$\mathrm{pH}$ & TECNOPON/ LUCA - 210 & \\
Turbidez & Del Lab/ DLT - WV & \\
\hline Oxigênio Dissolvido, OD & $4500-\mathrm{O} . \mathrm{C}$ & \\
Demanda Bioquímica de Oxigênio, & $5210-\mathrm{B}$ & APHA (1998) \\
DBO & $5220-\mathrm{D}$ & \\
Demanda Química de Oxigênio, & $2540-\mathrm{B}$ & \\
Sólidos Totais, ST & $2540-\mathrm{E}$ & \\
Sólidos Totais Fixos e Voláteis & & \\
\hline
\end{tabular}

A análise de coliformes totais e termotolerantes seguiu o sugerido pelo Manual Prático de Análise de Água da Fundação Nacional de Saúde - FUNASA (BRASIL, 2009, p.21-23).

A temperatura é um parâmetro importante visto que tem influência nas reações químicas, bioquímicas, processos biológicos, toxicidade dos elementos e substâncias e solubilidade de gases como $\mathrm{O}_{2}$ e $\mathrm{H}_{2} \mathrm{~S}$ (VON SPERLING, 2005). Para os organismos aquáticos existe um limite de tolerância térmica superior e inferior, temperaturas ótimas para o crescimento, além de limitações de temperatura para migração, desova e incubação dos ovos, caracterizando assim a importância desse parâmetro (CETESB, 2009). Adicionalmente, uma das causas antropogênicas da elevação da temperatura da água está relacionada aos despejos industriais nos corpos hídricos (NUNES, 2012).

A condutividade elétrica pode ser medida em $\mu \mathrm{Scm}^{-1}$ (micro Siemens $/ \mathrm{cm}$ ) e neste caso, representa a capacidade da água em conduzir corrente elétrica. Por indicar a quantidade de sais na forma de íons dissociados existentes na coluna de água, este parâmetro também sugere uma medida indireta da concentração de poluentes, em que a concentração superior a $100 \mu \mathrm{Scm}^{-1}$ geralmente está relacionada a ambientes impactados (CETESB, 2009).

$\mathrm{O} \mathrm{pH}$ é um parâmetro importante pois influencia diretamente os ecossistemas aquáticos naturais devido aos efeitos que este causa sobre a fisiologia de diversas espécies (VON SPERLING, 2005), além corroborar para a precipitação de elementos químicos tóxicos como metais pesados, e exercer efeitos sobre a solubilidade de nutrientes (WEINER, 2000; FARAGALLAH et al.,2009).

A turbidez representa a capacidade do ambiente hídrico em absorver e espalhar a passagem de um feixe de luz. Esse processo de absorção e espalhamento ocorre pela presença de sólidos suspensos com tamanho superior ao comprimento de onda aplicado. São exemplos de sólidos que promovem turbidez: compostos orgânicos, partículas inorgânicas de silte, areia e argila; além de organismos como algas, bactérias, plâncton, etc (CETESB, 2009). 
Em relação ao oxigênio dissolvido, sua presença na água se faz importante visto que está relacionado à sobrevivência dos seres aquáticos aeróbicos e a decomposição biológica da matéria orgânica (ESTEVES, 2011). Características hidráulicas, velocidade do curso hídrico e a fotossíntese de algas são fontes importantes de oxigênio na água (ODUM, 2001; FARAGE, 2009; ESTEVES, 2011).

A Demanda Bioquímica de Oxigênio, também conhecida por DBO padrão ou DBO5 $20^{\circ} \mathrm{C}$, representa a quantidade de oxigênio dissolvido, necessária aos microrganismos aeróbios para a estabilização da matéria orgânica biodegradável; quanto maior a presença de matéria biodegradável, maior será o valor da DBO (MACÊDO, 2006). Os métodos de ensaio laboratorial da DBO possuem algumas variações conforme as características do fluido que se deseja analisar, sendo possível efetuar o ensaio pelos métodos do Permanganato de Potássio, Iodométrico ou Winkler, Eletrolítico e Respirométrico ou Manométrico (APHA, 1998).

A DQO é um parâmetro utilizado para a mensuração da fração orgânica, por meio de uma oxidação química da matéria orgânica (e de parte da fração inerte da matéria) de águas superficiais e residuárias (APHA, 1998).

A análise de sólidos totais pode compreender as frações dissolvida, particulada, fixa e volátil. De modo geral, o processo de separação dos sólidos envolve o método gravimétrico com adoção de técnicas de filtração, secagem, evaporação e calcinação. Quando em excesso, os sólidos prejudicam a vida aquática, podem servir de substrato para bactérias e sedimentar no leito de fundo de modo a desencadear processos de degradação anaeróbia (CETESB, 2009).

\section{Análise dos resultados}

A avaliação dos resultados foi realizada segundo três óticas:

(i) Avaliação Visual: descrição dos aspectos visuais dos pontos monitorados e respectivas áreas de contribuição de modo a observar (se ausente ou presente) a conservação das margens do rio, processos de erosão e assoreamento, presença de resíduos sólidos e cor aparente da água;

(ii) Avaliação da Qualidade: salienta-se que a sub-bacia em estudo está enquadrada na classe II, segundo a Portaria SUREHMA n¹7/1991 (PARANÁ, 1991), e os parâmetros de pH, turbidez, OD e DBO estão previstos nas classes de enquadramentos da Resolução CONAMA $n^{\circ} 357 / 2005$ (BRASIL, 2005). Assim, tais parâmetros foram avaliados quanto a sua situação em conformidade ou desconformidade com a classe II de enquadramento. Demais parâmetros mensurados foram avaliados segundo recomendações propostas por pesquisadores e instituições. A Tabela 3 mostra detalhes da qualidade exigida para cada classe de enquadramento referente à Resolução mencionada, e também sugere padrões de qualidade para parâmetros não previstos pela mesma. 


\section{Tabela 3 - Classificação de parâmetros de qualidade da água a segundo Resolução CONAMA n³57/2005, e recomendações sugeridas pela CETESB, e Von Sperling (2005)}

\begin{tabular}{|c|c|c|}
\hline Parâmetro & Faixa & Referência \\
\hline $\mathrm{pH}$ & Classe I, II, III e IV: 6,0 - 9,0 & \multirow{4}{*}{$\begin{array}{l}\text { CONAMA n }{ }^{\circ} 357 / 2005 \\
\quad(\text { BRASIL, 2005) }\end{array}$} \\
\hline Turbidez & $\begin{array}{c}\text { Classe I } \leq 40 \text { UNT } \\
\text { Classe II } \leq 100 \text { UNT } \\
\text { Classe III e IV }>100 \text { UNT }\end{array}$ & \\
\hline OD & $\begin{array}{l}\text { Classe I } \geq 6 \mathrm{mgL}^{-1} \\
\text { Classe II } \geq 5 \mathrm{mgL}^{-1} \\
\text { Classe III } \geq 4 \mathrm{mgL}^{-1} \\
\text { Classe IV }>2 \mathrm{mgL}^{-1}\end{array}$ & \\
\hline $\mathrm{DBO}$ & $\begin{aligned} \text { Classe I } & \leq 3 \mathrm{mgL}^{-1} \\
\text { Classe II } & \leq 5 \mathrm{mgL}^{-1} \\
\text { Classe III } & \leq 10 \mathrm{mgL}^{-1} \\
\text { Classe IV } & >10 \mathrm{mgL}^{-1}\end{aligned}$ & \\
\hline $\begin{array}{l}\text { Condutividade } \\
\text { elétrica }\end{array}$ & $\begin{array}{l}\text { Não Impactado } \leq 100 \mu \mathrm{Scm}^{-1} \\
\text { Impactado }>100 \mu \mathrm{Scm}^{-1}\end{array}$ & CETESB (2009) \\
\hline$r=\frac{D Q O}{D B O}$ & $\begin{array}{c}\text { Elevada biodegradabilidade: } \mathrm{r}<2,5 \\
\text { Média biodegradabilidade: } 2,5 \leq \mathrm{r} \leq 3,5 \\
\text { Material inerte: } 3,5<\mathrm{r} \leq 5,0\end{array}$ & VON SPERLING (2005) \\
\hline
\end{tabular}

(iii) Avaliação Estatística: que compreendeu média, desvio padrão, coeficiente de variação e Correlação Linear de Pearson. Quanto a Correlação Linear de Pearson, optou-se por discutir os resultados que apresentaram valores de $\mathrm{r} \pm 0,7$. Para o coeficiente de variação $(\mathrm{CV})$ foram realizadas análises segundo os pressupostos de Fonseca e Martins (1996) classificando os coeficientes em baixa dispersão $(C V \leq 10 \%)$, média dispersão $(10 \%<C V \leq 20 \%)$ e alta dispersão $(C V>20 \%)$.

\section{Resultados e discussão}

\section{(i) Avaliação Visual}

Através da caracterização visual dos pontos amostrais constatou-se (Figura 2):

P1: moradias muito próximas das margens; banco de areia; cor aparente da água marrom após eventos de precipitação, mas translúcida em períodos de estiagens.

P2: presença de resíduos sólidos; e cor aparente da água cinza.

P3: margens do rio com predomínio de vegetação; cor aparente da água cinza a marrom claro.

P4: margens do rio com predomínio de vegetação; cor aparente da água marrom após eventos de precipitação, mas translúcida em períodos de estiagens.

P5: banco de areia; margem erodida com um desnível de cerca de $10 \mathrm{~m}$; cor aparente variando de marrom claro a cinza. 


\section{Figura 2 - Aspectos visuais dos pontos de monitoramento na sub- bacia do rio Pinhalzinho II. (A) ponto 1, (B) ponto 2, (C) ponto 3, (D) ponto 4, e (E) ponto 5}

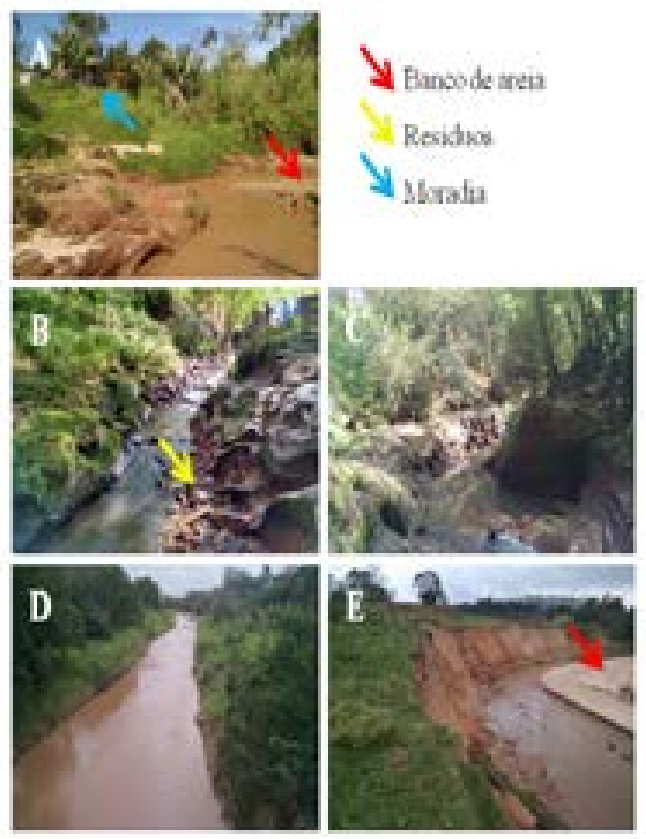

Os autores (2016).

Trabalho anterior já havia constatado elevada degradação nas cabeceiras de drenagem e no curso médio do rio Pinhalzinho II, situado na área urbana: presença de lixo nas margens do rio, e água com cor aparente escura, além da presença de óleo e espumas na superfície da água, e odor acentuado (FRANÇA JUNIOR; VILLA, 2013). Esses autores classificaram esse córrego como classe E, ou seja, péssimo grau de preservação, segundo metodologia proposta por Gomes et al., (2005).

Os bancos de areia decorrentes de processos erosivos das margens do rio e do transporte de sedimentos no canal, evidenciados nos pontos 1 e 5, também foram observados em estudos desenvolvidos por França Junior (2010) e Botari et al. (2016). Para os autores, o elevado assoreamento do canal é devido à ocupação urbana e áreas de pastagens, juntamente com a baixa preservação da vegetação (FRANÇA JUNIOR, 2010; BOTARI et al., 2016). Adicionalmente, Botari et al., (2016) verificaram a presença de tubulação de esgoto em estudo desenvolvido a montante do ponto 3.

Fonseca e Czuy (2005) afirmam que a região Noroeste do Paraná (Formação Caiuá) contém solos friáveis com alta suscetibilidade à erosão e de baixo teor de argila, o que motivou os autores a classificar a região quanto à capacidade de uso do solo para práticas agrícolas em categorias como inapta e uso restrito. Segundo Fonseca e Czuy (2005), a sub-bacia do rio Pinhalzinho, em Umuarama, foi categorizada como "inapta com potencial de erodibilidade e afloramento rochoso".

A erodibilidade e consequentes assoreamentos de rios situados na Formação Caiuá, também foram verificadas por Schneider et al., (2011) durante a avaliação de córrego Romeira em Maringá, uma sub-bacia com nível significativo de preservação, entretanto com desmatamento em uma pequena parte da nascente, que colabora para a geração de processos erosivos. 


\section{(ii) Avaliação da Qualidade}

Os resultados obtidos para coliformes totais e termotolerantes foram positivos para todos os pontos amostrais, nas diferentes coletas. Os testes presuntivos e confirmativos indicaram um índice de NMP/100 mL superior a 16 (com limites de 8 ao infinito). A Resolução CONAMA n ${ }^{\circ}$ 357/2005, sugere o padrão de coliformes termotolerantes prescritos pela Resolução CONAMA $n^{\circ}$ 274/2000, para as atividades de contato primário. Entretanto, devida a robustez do método adotado, não é possível precisar se a presença de coliformes termotolerantes está em conformidade legal ou não com a Resolução supracitada. Ronquim (2010) realizou análise bacteriológica no rio Mimosa (ou ponto 2 no presente trabalho) e constatou resultados positivos para coliformes totais e fecais.

A média de temperatura para os pontos amostrados na foi de $26,06^{\circ} \mathrm{C}$. Takeda, Mendes e Marin (2011) desenvolveram entre 2010 e 2011, estudo na região logo a montante do ponto 3 e determinaram temperatura máxima de $25,9^{\circ} \mathrm{C}$ e mínima de $18,86^{\circ} \mathrm{C}$. Alves et al., (2008) registraram máxima de $28,8^{\circ} \mathrm{C}$ e mínima de $16,6^{\circ} \mathrm{C}$ em monitoramento realizado no rio Pirapó, situado em Maringá no Noroeste paranaense. De acordo com Odum (2001), a maioria dos organismos aquáticos possui pouca tolerância às variações de temperatura de modo que pequenas elevações de $5^{\circ} \mathrm{C}$ podem alterar em $50 \%$ os efeitos tóxicos que certas substâncias causam a esses organismos.

Em termos de condutividade elétrica (CE), a análise doa resultados (Figura 3) permite afirmar que na coleta 1 , os resultados obtidos para os pontos 1,2, 4 e 5 foram acima do recomendado pela CETESB (2009), estando apenas o ponto 3 dentro do limite estabelecido. Na coleta 2, por sua vez, todos os pontos amostrais indicaram ser ambientes impactados (Figura 3). Quanto a coleta 3, esta não foi possível mensurar diante de problemas com o equipamento. Entretanto, os altos valores de condutividade elétrica podem ser originários de ações antrópicas (esgotos domésticos e descargas industriais). Durante avaliação do potencial de poluição do rio Atibaia (SP) por despejos industriais, Castanha et al., (2015) mensuraram valores de condutividade de 2.558,33 $\mu \mathrm{Scm}^{-1}$ no ponto de lançamento, e de $306,57 \mu \mathrm{Scm}^{-1}$ a 800 metros a jusante.

Segundo a Resolução CONAMA n ${ }^{\circ} 357 / 2005$, para todas as classes do enquadramento dos corpos hídricos, o $\mathrm{pH}$ varia de 6,0 - 9,0 estando todos os pontos das diferentes coletas da presente pesquisa dentro dos padrões da norma. De forma semelhante, Alves et al., (2008) determinaram valores de $\mathrm{pH}$ em conformidade com a Resolução supracitada durante diagnóstico da qualidade da água realizado no rio Pirapó, em Maringá-PR, com variação de 7,2 a 8,4. Observa-se que independentemente do grau de poluição do corpo hídrico o parâmetro de $\mathrm{pH}$ tem se mantido estável (KNAPIK, 2009; FARAGE, 2009; VILLA, 2010; CAETANO; MARTINS; MERLINI, 2011; HABERLAND et al., 2012; CASTANHA et al., 2015). Isso ocorre devido ao efeito tampão do ambiente aquático, o qual é regido pelo potencial de acidez e de alcalinidade do meio, de modo a impedir e/ou minimizar possíveis alterações extremas do $\mathrm{pH}$ através da adição de ácidos ou bases fortes (WEINER, 2000; NASCIMENTO et al., 2009). 


\section{Figura 3 - Variação do parâmetro condutividade elétrica na sub-bacia do rio Pinhalzinho II}

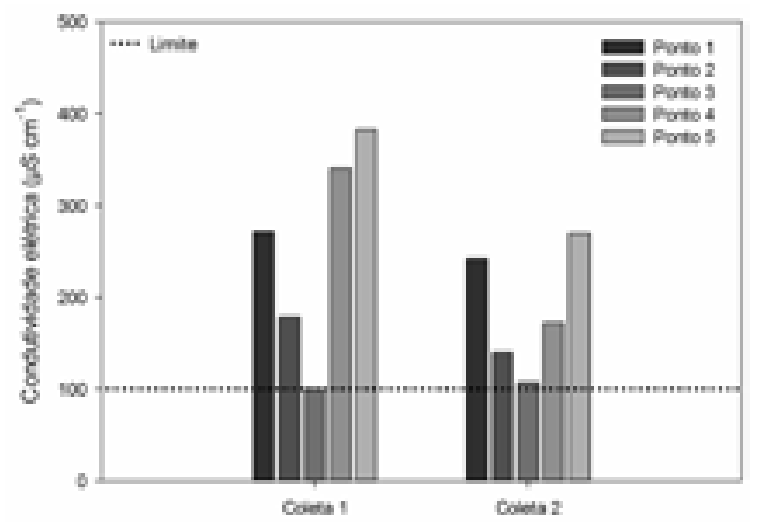

Fonte: Os autores (2016).

A Figura 4 apresenta os resultados de turbidez mensurados durante as coletas 1,2 e 3. Conforme já mencionado, o rio Pinhalzinho II está enquadrado na classe II (PARANÁ, 1991), a qual permite a concentração máxima de 100 UNT (BRASIL, 2005). Logo, pela análise da Figura 4, observa-se que na coleta 1 , todos os pontos apresentaram-se de acordo com a classe II; na coleta 2 somente o ponto 2 estava em conformidade; e na coleta 3, apenas os pontos 2 e 3 estavam em conformidade legal. Em outras palavras, 53,3\% da amostragem apresentou-se na classe II de enquadramento. Em um ano de monitoramento da turbidez a montante do ponto 3, Takeda, Mendes e Marin (2011), obtiveram 83,3\% da amostragem em conformidade com a classe II. Haberland et al., (2012), ao avaliarem a qualidade da água do rio das Antas sob influencia da urbanização (Irati-PR), constataram que $100 \%$ da amostragem do parâmetro turbidez manteve-se em conformidade com a classe do rio, sendo a turbidez máxima registrada de 33 UNT. Alves et al., (2008) registraram no rio Pirapó (Maringá - PR) a variação do parâmetro de 10 a 180 UNT.

\section{Figura 4 - Variação do parâmetro de turbidez na sub-bacia do rio Pinhalzinho II}

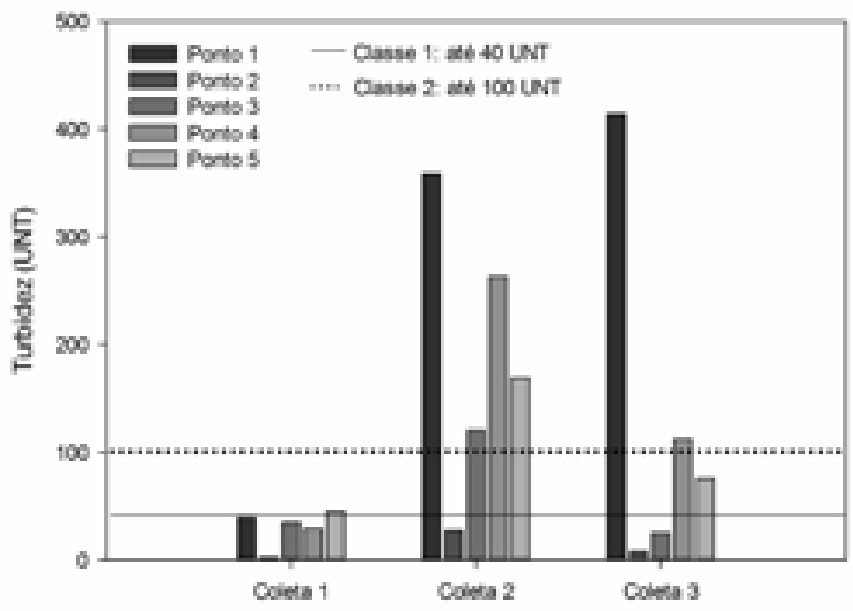

Fonte: Os autores (2016). 
Ainda na análise da Figura 4, salienta-se que os elevados valores de turbidez encontrados durante a coleta 2 , podem ser atribuídos ao fato de que a medição do parâmetro ocorreu em um período posterior a chuvas incessantes e intensas, fato que corrobora com dados do CEMADEN (2015) em que a precipitação no município foi de $84,32 \mathrm{~mm}$ dez dias antecedentes a coleta. Logo, saliente-se que em épocas chuvosas há o carreamento de material particulado e a resuspensão do leito de fundo para os corpos hídricos, em especial os rasos. Takeda, Mendes e Marin (2011) determinaram a montante do ponto 3, valores de turbidez acima da classe II após dias chuvosos nos meses de março (150,92 UNT) e maio (265,56 UNT) de 2010. Outro fato a ser considerado quanto a Figura 4 é que obras com maquinário estavam sendo realizadas a montante do ponto 1 nas coletas 2 e 3 , justificando os resultados encontrados especialmente no ponto 1 .

A Figura 5 apresenta os valores de OD mensurados por este estudo, e de forma semelhante ao analisado com a turbidez, para o OD a classe II exige pelo menos $5 \mathrm{mgL}^{-1}$ (BRASIL, 2005). Assim, na avaliação da Figura 5, observa-se que apenas o ponto 5 (durante as coletas 1 e 3) apresentouse em desconformidade legal com o disposto na Portaria SUREHMA n¹7/1991 (PARANÁ, 1991). As demais mensurações de oxigênio dissolvido apresentaram-se em conformidade legal, inclusive com concentrações do parâmetro em melhor qualidade que o mínimo exigido.

\section{Figura 5 - Variação do parâmetro Oxigênio Dissolvido na sub-bacia do rio Pinhalzinho II}

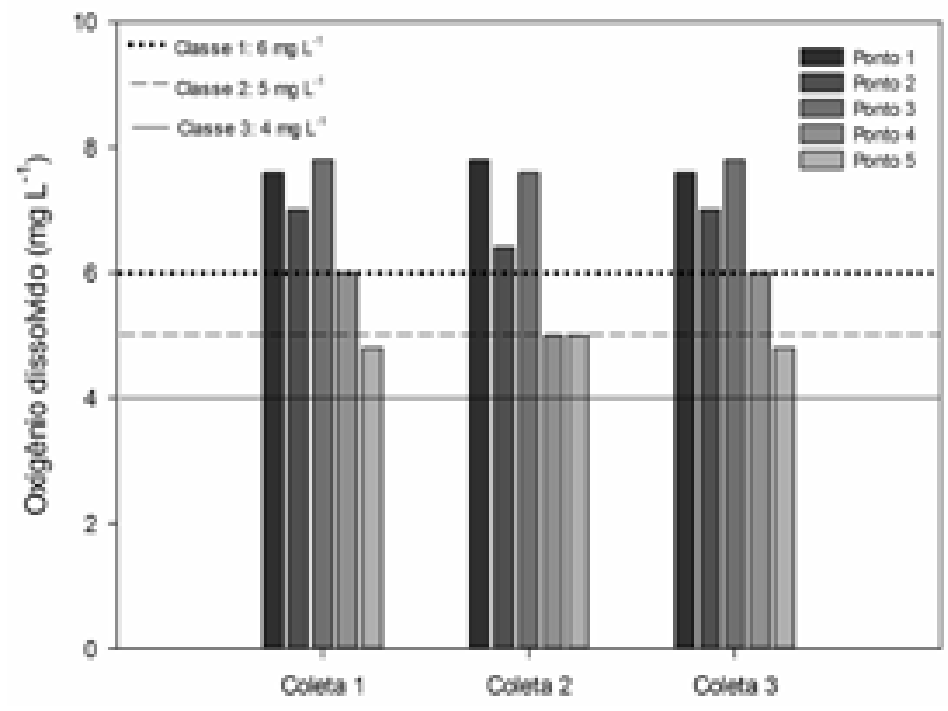

Os autores (2016).

De modo geral, para o OD houve o predomínio da qualidade mínima exigida em $80 \%$ do período total amostrado. Takeda, Mendes e Marin (2011) obtiveram 50\% da amostragem na classe II em monitoramento da montante do ponto 3. Em estudo desenvolvido na sub-bacia rio das Antas, sob influência da cidade de Irati-PR com população de 56.207 (IBGE, 2010), a concentração de OD manteve-se de acordo com a classe do rio em $96 \%$ da amostragem (HABERLAND et al., 2012). Por meio do monitoramento do OD em afluentes do rio Pirapó (Maringá-PR) foi observado que 97,4\% da amostragem apresentou-se em conformidade legal com a classe de enquadramento (SCHNEIDER et al., 2011), e que 98,5\% da amostragem de OD realizada no canal principal do rio manteve-se em conformidade com a classe, entretanto, foi observado o predomínio das concentrações mínimas do parâmetro nos pontos amostrados 
sob influência da urbanização (ALVES et al., 2008). O parâmetro de OD sugere o nível de biodiversidade aquática, concentração inferir a $2 \mathrm{mgL}^{-1}$ envolve mortandade de espécies menos tolerantes (LEVIN et al., 2009).

Em relação aos resultados obtidos para a DBO, conforme pode ser visualizado na Figura 6, apenas os pontos 1, 2 e 3 da coleta 1 ; ponto 3 da coleta 2 e pontos 1 e 3 da coleta 3 apresentaram concentrações de DBO em conformidade com a classe II da Resolução CONAMA n 357/2005, a qual estabelece a concentração máxima de $5 \mathrm{mgL}^{-1}$. Todas as demais combinações de pontos e coletas apresentaram-se em desconformidade com o máximo de DBO legalmente permitido. Em suma, quanto ao parâmetro de DBO, apenas 40\% dos dados apresentaram-se de acordo com a classe II, e 60\% em desacordo. Takeda, Mendes e Marin (2011), ao monitorarem por um ano a montante do ponto 3, em termos de $\mathrm{DBO}$ os autores determinaram que $100 \%$ da amostragem permaneceu em conformidade legal com a classe II. Schneider et al., (2011) também verificaram $100 \%$ da amostragem do parâmetro DBO realizada em afluentes do rio Pirapó em conformidade com a classe, sendo que entre os afluentes analisados estava o rio Mandacaru, o qual possui uso e ocupação urbano em sua área de drenagem.

\section{Figura 6 - Variação do parâmetro Demanda Bioquímica de Oxigênio na sub-bacia do rio Pinhalzinho II}

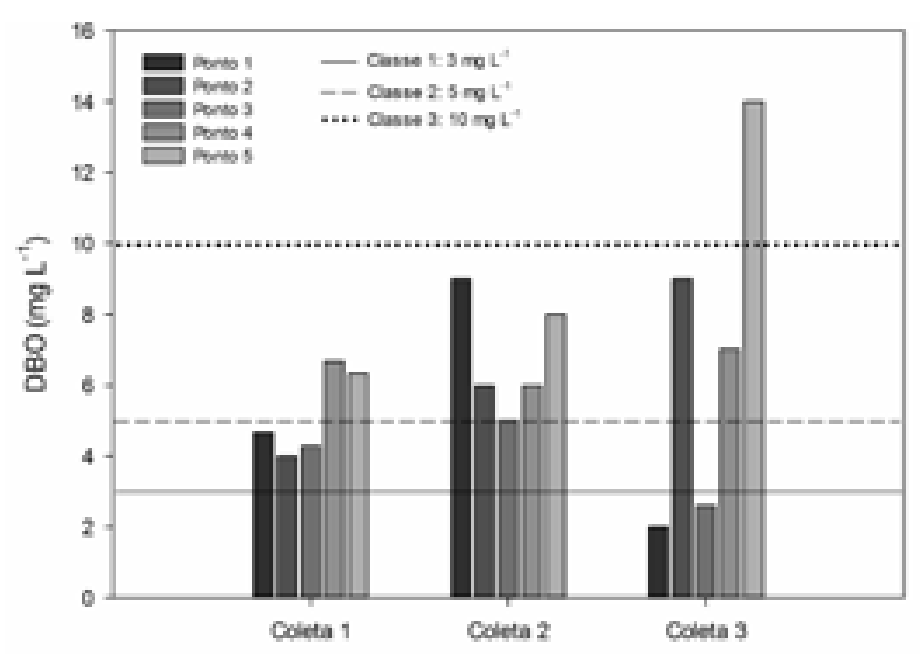

Fonte: Os autores (2016).

Ainda com relação aos resultados de $\mathrm{DBO}$, com exceção dos pontos 1 e 3 da terceira coleta, o restante dos resultados podem indicar despejos de origem orgânica como efluente doméstico, uma vez que foi detectado contaminação por coliformes totais e fecais durante todas as coletas e para todos os pontos, conforme apresentado anteriormente. Haberland et al., (2012) avaliaram a influencia do uso urbano do solo na qualidade da água do rio das Antas (Irati-PR) e evidenciaram poluição da água por esgotos domésticos diante dos resultados de $\mathrm{DBO}$, fósforo e coliformes totais e fecais. Alves et al., (2008) também associaram os maiores valores de DBO mensurados no rio Pirapó (Maringá-PR) com possível contaminação por esgoto doméstico.

Tratando-se de DQO, os resultados para a primeira coleta foram de 7,33 $\mathrm{mg} \mathrm{L}^{-1} ; 10,67$ $\mathrm{mg} \mathrm{L}^{-1} ; 20,67 \mathrm{mg} \mathrm{L}^{-1} ; 54,00 \mathrm{mg} \mathrm{L}^{-1}$ e 74,00 $\mathrm{mg} \mathrm{L}^{-1}$ para os pontos 1, 2, 3, 4 e 5, respectivamente. $\mathrm{Na}$ coleta 2, para os pontos 1, 2, 4 e 5, obteve-se respectivamente, $17,33 \mathrm{mgL}^{-1} ; 14,00 \mathrm{mgL}^{-1}$; $44,00 \mathrm{mgL}^{-1}$ e $77,33 \mathrm{mgL}^{-1}$ (Figura 7). O resultado do ponto 3 (segunda coleta) foi descartado, 
porque que não foi possível mensurar seu valor, assim como não foi possível realizar a análise de DQO durante a coleta 3. Caetano, Martins e Merlini (2011) determinaram DQO média de $24,4 \mathrm{mgL}^{-1}$ a montante do ponto 3 .

\section{Figura 7 - Variação do parâmetro Demanda Química de Oxigênio na sub-bacia do rio Pinhalzinho II}

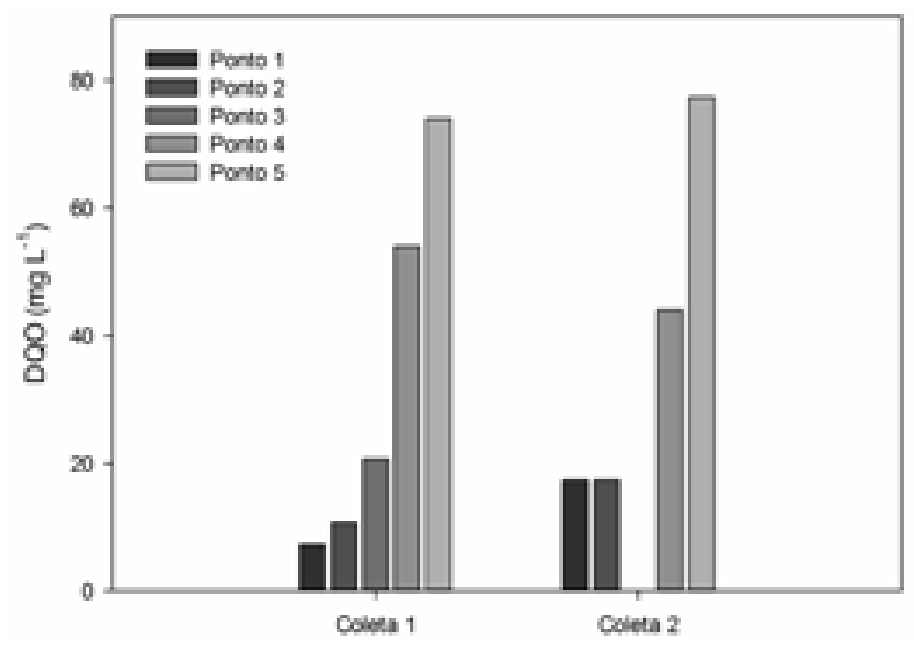

Fonte: Os autores (2016).

Nesse caso, observa-se que os pontos monitorados apresentaram um comportamento típico de concentração de DQO crescente da montante para a jusante, fato bastante lógico. Entretanto, as altas concentrações de DQO, determinadas nos pontos 4 e 5 , sugerem elevadas frações de matéria orgânica recalcitrante e/ou compostos inertes. Fazendo uma analogia com o potencial de biodegradabilidade (r), bastante empregado na definição da técnica de tratamento de efluentes (VON SPERLING, 2005), foi determinada elevada biodegradabilidade nos pontos $1(\mathrm{r}=1,1)$ e $2(\mathrm{r}=1,9)$, e predomínio de material inerte nos pontos $3(\mathrm{r}=5,2), 4(\mathrm{r}=7,5)$ e $5(\mathrm{r}$ $=8,0)$. A área nas proximidades do ponto 5 apresenta considerável número de empreendimentos industriais; Villa $(2010)$ estimou valores médios de DBO e DQO de respectivamente, 4,5 mgL $\mathrm{m}^{-1}$ e $128 \mathrm{mgL}^{-1}(\mathrm{r}=28,4)$.

Para os sólidos totais (ST), foram encontrados resultados na coleta 3 para os pontos 1,2,3, 4 e 5, respectivamente, de 1040,0 mgL $\mathrm{m}^{-1} ; 178,0 \mathrm{mgL}^{-1} ; 108,0 \mathrm{mgL}{ }^{-1} ; 316,0 \mathrm{mgL}^{-1}$ e 414,0 mgL $\mathrm{m}^{-1}$ (ver Figura 8). A Resolução CONAMA n ${ }^{\circ} 357 / 2005$ prevê para sólidos dissolvidos totais de até $500 \mathrm{mgL}^{-1}$; os corpos hídricos são classificados em classe I, II e III. Porém não há classificação nessa Resolução para sólidos totais. $\mathrm{O}$ alto valor encontrado para o ponto 1 pode estar ligado diretamente às obras com maquinário que estavam acontecendo a montante do local. Villa (2011a) determinou, no curso médio do rio Pinhalzinho II, o valor médio de $10,4 \mathrm{mgL}^{-1}$ de sólidos totais no período de 2008 a 2009. 


\section{Figura 8 - Variação do parâmetro Sólidos Totais, Fixos e Voláteis na sub-bacia do rio Pinhalzinho II}

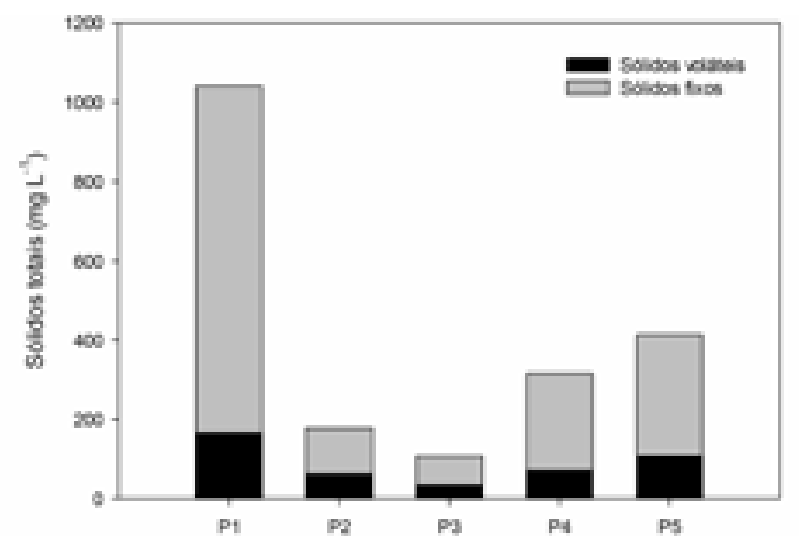

Fonte: Os autores (2016).

Com exceção do ponto 1, que estava sob influência de obras com maquinário pesado nas proximidades, os demais pontos monitorados apresentaram valores moderados de sólidos totais, mas sempre com composição predominante da fração de sólidos fixos. Isso provavelmente está relacionado à Formação Caiuá, com alto teor de areia (FONSECA; CZUY, 2005). Assim como a sub-bacia do Pinhalzinho II, a do rio das Antas (Formação Irati) também está sob influência da urbanização e apresentou concentração de sólidos totais relativamente baixa, com máximo de

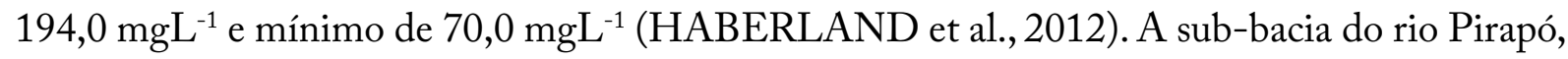
situada em Maringá - PR (Formação Caiuá), por sua vez, apresentou concentração de sólidos totais variável entre 94 e $588 \mathrm{mgL}^{-1}$ (ALVES et al., 2008).

\section{(iii) Avaliação Estatística}

Para analisar e verificar o grau de dispersão entre os pontos amostrais das coletas foram feitas análises estatísticas. A Tabela 4 apresenta a média e o desvio padrão para os parâmetros de turbidez, $\mathrm{pH}, \mathrm{OD}$ e $\mathrm{DBO}$, partindo do pressuposto de que cada ponto amostral estava sob as mesmas condições, durante uma mesma coleta.

\section{Tabela 4 - Média e Desvio Padrão segundo os parâmetros turbidez, $\mathrm{pH}, \mathrm{OD}$ e DBO}

\begin{tabular}{cccccc}
\hline \multirow{2}{*}{ Parâmetros } & \multicolumn{5}{c}{ Pontos Amostrais } \\
\cline { 2 - 6 } & P1 & P2 & P3 & P4 & P5 \\
\hline Turbidez $(\mathrm{UNT})$ & $270,9 \pm 165,02$ & $12,47 \pm 10,54$ & $59,93 \pm 42,65$ & $134,6 \pm 96,94$ & $96,53 \pm 52,72$ \\
$\mathrm{pH}$ & $7,03 \pm 0,84$ & $6,86 \pm 0,64$ & $6,93 \pm 0,68$ & $6,91 \pm 0,65$ & $6,89 \pm 0,64$ \\
OD $\left(\mathrm{mgL}^{-1}\right)$ & $7,67 \pm 0,09$ & $6,80 \pm 0,28$ & $7,73 \pm 0,09$ & $5,67 \pm 0,47$ & $4,87 \pm 0,09$ \\
DBO $\left(\mathrm{mgL}^{-1}\right)$ & $5,22 \pm 2,88$ & $6,33 \pm 2,05$ & $3,96 \pm 1,00$ & $6,56 \pm 0,42$ & $9,44 \pm 3,29$ \\
\hline
\end{tabular}

Fonte: Os autores (2016).

A montante do P3, estudos determinaram turbidez média mensal desde 59,56 UNT (TAKEDA; MENDES; MARIN, 2011) e de 12 UNT (CAETANO; MARTINS; MERLINI, 2011). Assim como para o ponto 5, pesquisa anterior mensurou o valor médio de turbidez 
de 13,6 UNT (VILLA, 2010), consideravelmente mais baixo que o estimado pelo presente estudo (turbidez média do ponto $5=96,53 \mathrm{UNT}$ ). Adicionalmente, em diagnóstico anterior da qualidade da água feito nas proximidades do ponto 3 , foi determinado o valor médio de $\mathrm{pH}$ de 6,96 (TAKEDA; MENDES; MARIN, 2011) e de 5,89 (CAETANO; MARTINS; MERLINI, 2011). Além de concentração média, máxima e mínima de $\mathrm{OD}$, respectivamente de $4,55 \mathrm{mgL}^{-1}$, 7,00 $\mathrm{mgL}^{-1}$ e 2,45 mgL-1, e concentração média de DBO de 2,94 mgL-1 (TAKEDA; MENDES; MARIN, 2011) e 11,9 $\mathrm{mgL}^{-1}$ (CAETANO; MARTINS; MERLINI, 2011). Em diagnóstico da qualidade da água realizado no rio Pirapó (Maringá - PR), foi mensurada a concentração mínima de DBO de 2,0 $\mathrm{mgL}^{-1}$ e máxima de $9,21 \mathrm{mgL}^{-1}$ (ALVES et al., 2008).

A Figura 9 apresenta os resultados de coeficiente de variação indicando o grau de dispersão dos parâmetros supracitados. Por meio da Figura 9 juntamente com a Tabela 4, que contém as demais informações estatísticas, torna-se possível realizar uma avaliação quanto ao grau de dispersão dos pontos amostrais para os parâmetros em análise.

\section{Figura 9 - Coeficiente de Variação segundo os parâmetros turbidez, $\mathrm{pH}, \mathrm{OD}$ e DBO}

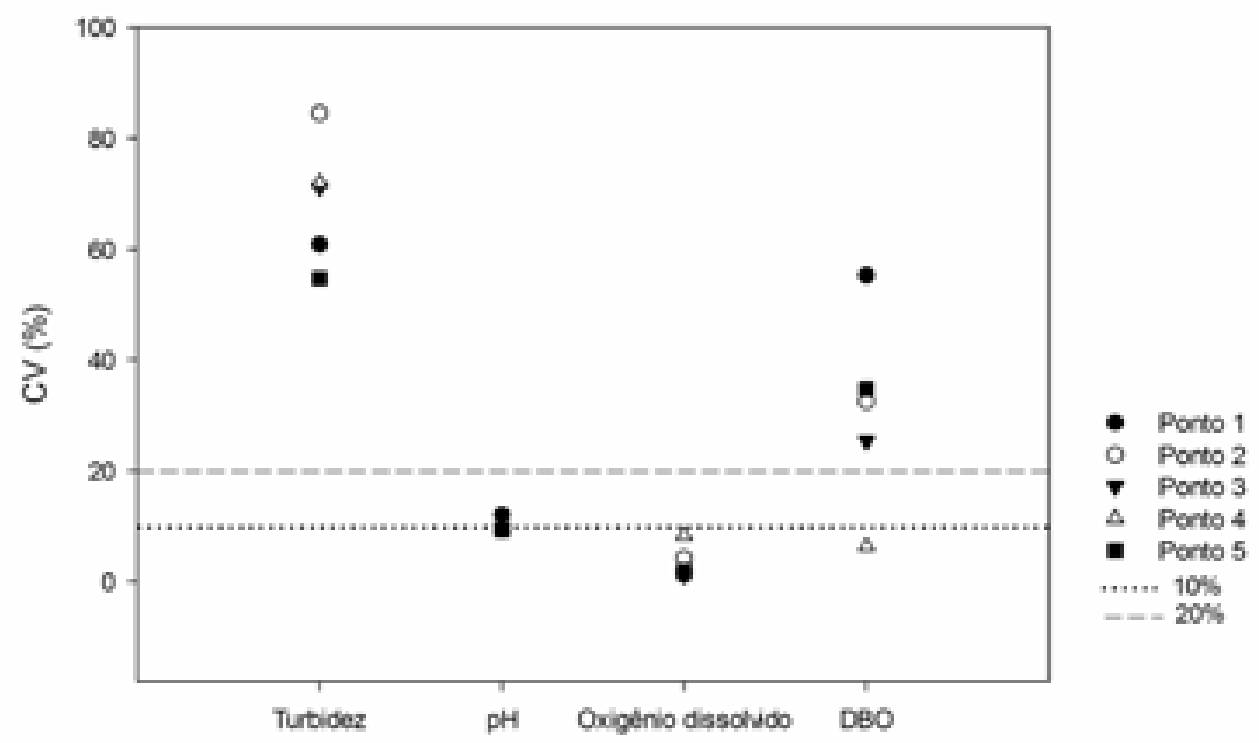

Fonte: Os autores (2016).

Assim, constatou-se que a turbidez apresentou alta dispersão para todos os pontos amostrais $(60,91 \%, 84,51 \%, 71,16 \%, 72,02 \%, 54,62 \%$ respectivamente para os pontos $1,2,3$, 4 e 5). Sendo que para a maior dispersão observada, ponto 2 , obteve-se uma média de 12,47 UNT e um desvio padrão de 10,54. Como salientado na avaliação qualitativa dos resultados (item ii), reforça-se que os valores de turbidez variaram consideravelmente devido aos eventos de precipitação ou ausência deles, e por obras de infraestrutura realizadas nos proximidades e no próprio local do ponto 1 . Takeda; Mendes, Marin, (2011), também verificaram a influencia de eventos de precipitação sobre a qualidade da água em termos de turbidez. 
Para o pH, com exceção do ponto 1 que apresentou média dispersão (12,02\%), os demais pontos apresentaram baixa dispersão, reforçando o grau de estabilidade do parâmetro conforme sugerido pelos resultados de qualidade da água.

Já para o OD, o grau de dispersão encontrado para os pontos 1,2, 3, 4 e 5 foi respectivamente de 1,23\%,4,16\%,1,22\%, 8,31\% e 1,93\%, ou seja, baixa dispersão, caracterizando dados homogêneos. Os valores médios de OD sugerem uma determinada qualidade do ambiente hídrico, ou mesmo uma estabilidade nas formas de introdução do oxigênio neste ambiente. Schneider et al., (2011) relacionaram elevados valores de OD mensurados no rio Pirapó (Maringá - PR) com uma boa capacidade de autodepuração do rio.

Enquanto que para a DBO, com exceção do ponto 4 que apresentou baixa dispersão $(6,34 \%)$, a dispersão foi alta para o restante dos pontos $(55,26 \%, 34,46 \%, 25,37 \%, 34,89 \%$, respectivamente para os pontos 1, 2, 3 e 5), definindo dados heterogêneos, possivelmente, devido a aportes de matéria orgânica advindos das respectivas áreas de contribuição. Já em relação à matriz de Correlação Linear de Pearson, a Tabela 5 apresenta os resultados determinados.

Tabela 5 - Matriz de Correlação Linear de Pearson entre os parâmetros de temperatura, turbidez, condutividade elétrica (CE), pH, OD, DBO, DQO e ST

\begin{tabular}{ccccccccc}
\hline Parâmetros & Temperatura & Turbidez & $\mathbf{C E}$ & $\mathbf{p H}$ & $\mathbf{O D}$ & $\mathbf{D B O}$ & $\mathbf{D Q O}$ & $\mathbf{S T}$ \\
\hline Temperatura & 1 & $-0,03$ & 0,65 & $-0,19$ & $-0,78$ & 0,75 & 0,95 & $-0,08$ \\
Turbidez & & 1 & 0,49 & 0,92 & 0,19 & $-0,12$ & $-0,10$ & 0,94 \\
CE & & & 1 & 0,17 & $-0,73$ & 0,80 & 0,72 & 0,53 \\
pH & & & & 1 & 0,52 & $-0,42$ & $-0,35$ & 0,86 \\
OD & & & & & 1 & $-0,92$ & $-0,93$ & 0,19 \\
DBO & & & & & & 1 & 0,84 & 0,00 \\
DQO & & & & & & & 1 & $-0,15$ \\
ST & & & & & & & & 1 \\
\hline
\end{tabular}

Fonte: Os autores (2016).

A relação entre a temperatura e oxigênio apresentou $r=-0,78$, que representa correlação negativa significativa, ou seja, quanto menor a temperatura, maior a solubilidade do oxigênio. Já a correlação significativa positiva entre temperatura e $\mathrm{DBO}(\mathrm{r}=0,75)$ pode indicar que quanto maior a temperatura, maior a $\mathrm{DBO}$, visto que a elevação da temperatura até certo limite acelera os processos metabólicos de microrganismos, inclusive os que exercem a degradação da matéria orgânica.

Os valores de turbidez correlacionaram-se de forma significativa e positiva com os sólidos totais $(r=0,94)$. Ou seja, quanto maior a turbidez da água consequentemente maior será a presença de sólidos totais. Para Alves et al., (2008), a concentração de sólidos suspensos totais contribui para o aumento dos valores de turbidez e cor aparente da água. Contudo, deve-se salientar que os sólidos totais sumarizam as frações dissolvida e particulada, e no caso da turbidez especificamente, mede-se a fração particulada, fato que sugere que a fração particulada predomina sobre a fração dissolvida. A correlação negativa entre $O D$ e condutividade $(r=-0,73)$ sugere um estágio avançado de mineralização da matéria orgânica. Uma vez que a degradação biológica da matéria orgânica consome $\mathrm{O}_{2}$ e libera, ao ambiente aquático, formas inorgânicas (ex: $\mathrm{NO}_{2}^{-}, \mathrm{NO}_{3}^{-}, \mathrm{PO}_{4}^{-3}, \mathrm{Cl}^{-}$, entre outros) que promovem ou contribuem ao valor de condutividade. $\mathrm{O}$ que de certa forma corrobora 
com a correlação negativa entre $\mathrm{DBO}$ e $\mathrm{OD}(\mathrm{r}=-0,92)$ e com a correlação positiva entre a DBO e a condutividade $(\mathrm{r}=0,80)$. Ou seja, à medida que a $\mathrm{DBO}$ é exercida há um consumo de $\mathrm{OD}$ e um aumento de condutividade.

Salienta-se que a DQO também apresentou correlação positiva com a condutividade ( $\mathrm{r}$ $=0,72)$ e negativa com o OD $(r=-0,93)$. Isso se justifica pelo fato de ambas, $\mathrm{DBO}$ e DQO, mensurarem ou estimarem a matéria orgânica, cada qual via seu respectivo método. Nesse contexto, a DBO correlacionou-se positivamente com a DQO $(\mathrm{r}=0,84)$, já que a DBO estima a matéria orgânica e a DQO, matéria orgânica acrescida de uma parte da fração inerte.

\section{Conclusão}

Os estudos neste trabalho tiveram o objetivo de realizar um diagnóstico da qualidade do rio Pinhalzinho II em sua área de drenagem urbana em termos visuais, qualitativos, e estatísticos. A avaliação dos resultados permitiu identificar, no manancial: trechos erodidos com consequente propensão à formação de bancos de areia; cor aparente variável de marrom a cinza; e usos do solo variáveis entre urbano, industrial e agropecuário. Quanto à qualidade da água, observou-se: presença de coliformes termotolerantes; condutividade elevada; turbidez 53,3\% dentro da classe II, e bastante influenciada pelas chuvas na região e tipo de solo; OD $80 \%$ dentro da classe II; DBO 40\% dentro da classe II; DQO próxima de $80 \mathrm{mgL}^{-1}$ nos pontos a jusante; e pH estável.

Entre as análises estatísticas, pode-se afirmar que há predomínio dos sólidos totais na fração particulada, a julgar pela correlação entre sólidos totais e turbidez $(r=0,94)$; e que a matéria orgânica apresenta um estágio moderado de estabilização, dada a correlação entre DBO e condutividade $(r=0,80)$ e, consequentemente entre OD e condutividade $(r=-0,73)$.

Em suma, observa-se que a sub-bacia avaliada apresenta indícios de poluição da água devido à urbanização; como sugerem os resultados de coliformes, condutividade elétrica, DBO e DQO. Adicionalmente, por se tratar de um solo oriundo dos arenitos da Formação Caiuá, aliado aos poucos fragmentos de vegetação existentes na região, os processos erosivos são mais recorrentes. Logo, a partir dos resultados adquiridos, faz-se necessária a adoção de metas progressivas de recomposição das Áreas de Preservação Permanente como forma de proteção das margens, além de metas de despoluição hídrica para redução do teor orgânico, inorgânico e de coliformes.

\section{Referências Bibliográficas}

ABNT - Associação Brasileira de Normas Técnicas - NBR 9.898: Preservação e técnicas de amostragem de efluentes líquidos e corpos receptores - Procedimento. Rio de Janeiro, 1987.

ALVES, E. C.; SILVA, C, F.; COSSICH, E. S.; TAVARES, C. R. G.; SOUZA FILHO, E. E.; CARNIEL, A. Avaliação da qualidade da água da bacia do rio Pirapó - Maringá, Estado do Paraná, por meio de parâmetros físicos, químicos e microbiológicos. Acta Sci. Technol. Maringá, v.30, n.3, p.39-48, 2008.

APHA (American Public Health Association); AWWA (American Water Works Association); WPCF(Water Environment Federation). Standard Methods for the Examination of Water and Wastewater, 20ª Edition, Washington, D.C., 1998. 
ARAÚJO, A. M; MELO, M. C. V. Um plano de amostragem de qualidade d'água em estuários: caso do recife. Revista Brasileira de Recursos Hídricos, v.5. n.4, p.111-120, 2000 .

BOTARI, J. C.; BOTARI, A.; OLIVEIRA, B. C.; SANTOS, L. N.; DANELUZZI, N. S.; HATSUMURA, P. M. Análise ambiental urbana e proposta de intervenção nos bairros jardim Harmonia e Jardim Aratimbó do município de Umuarama região Noroeste do estado do Paraná. In: XIV International Conference of Engineering and Tecnology Education, Salvador, Brasil, 2016.

BRASIL. CONAMA - Conselho Nacional de Meio Ambiente. Resolução 357, de 17 de março de 2005. Brasília, 2005.

BRASIL. Manual Prático de Análise de Água. FUNASA. 3a ed. rev. Brasília: Fundação Nacional de Saúde, 2009.

CAETANO, I. C. S.; MARTINS, L. A.; MERLINI, L. S. Análise da qualidade da água e dos peixes do lago Aratimbó, Umuarama PR-Brasil. Arq. Ciênc. Saúde UNIPAR, Umuarama, v.15, n.2, p.149-157, 2011.

CALIJURI, M. L.; COUTO, E A.; SANTIAGO, A. F.; CAMARGO, R. A.; SILVA, M.D.F.M. Evaluation of the influence of natural and antrhopogenic processes on water quality in karstic region. Water Air Soil Pollut, v.223, p.2157-2168, 2012. DOI 10.1007/ s11270-011-1012-5.

CASTANHA. R. F.; ANGELIS, D. F.; BUTTURI-GOMES, D.; ANGELIS. D. A. Evaluation of the Atibaia River water quality using Lecane bulla as a test organism. Arq. Inst. Biol., São Paulo, v.82, p. 1-7, 2015.

CEMADEN - Centro Nacional de Monitoramento e Alertas de Desastres Nacionais. Ministério da Ciência,Tecnologia e Informação. Disponível em: <http://150.163.255.234/ salvar/mapa_interativo/interativo/grafico_CEMADEN.php?idpcd $=6382 \& m e n u=p e r i$ odo\&ordem $=$ crescente\&ordercampo $=a c c 96 h r \& b u s c a=\& u f=P R \& i d C i d a d e=4128104>$. Acesso em: 26 Ago. 2015.

CETESB - Companhia Ambiental do Estado de São Paulo. Significado Ambiental e Sanitário das Variáveis de Qualidade das Águas. Qualidade das Águas Superficiais no Estado de São Paulo. 2009.

CHU, M L.; KNOUFT, J. H.; GHULAM, A.; GUZMAN, J. A.; PAN, Z. Impacts of urbanization on river flow frequency: A controlled experimental modeling-based evaluation approach. Journal of Hydrology, v.495, p.1-12, 2013.

ESTEVES, F. A. Fundamentos de limnologia. 3 Ed. Interciência, 2011. 
FARAGALLAH,H.M.; ASKAR, A.I.; OKBAH,M.A.; MOUSTAFA, H.M.Physicochemical characteristics of the open Mediterranean sea water far about $60 \mathrm{Km}$ from Damietta harbor, Egypt. Journal of Ecology and The Natural Environment. v.1, n.5, p. 106-119, 2009.

FARAGE, J. A. P. Influência do uso e da ocupação do solo na qualidade da água e capacidade autodepurativa do rio Pomba. Dissertação (Mestrado em Engenharia Agrícola), Universidade Estadual de Viçosa, Minas Gerais, 2009.

FONSECA, F. P.; CZUY, D. C. Formação Arenito Caiuá: uso, ocupação do solo e problemas ambientais na região noroeste do Paraná. In: III Simpósio Nacional de Geografia Agrária - II Simpósio Internacional de Geografia Agrária Jornada Ariovaldo Umbelino de Oliveira - Presidente Prudente, 11 a 15 de novembro de 2005.

FONSECA,J. S.; MARTINS, G. A. Curso de Estatística. São Paulo. 6a ed., Atlas, 1996.

FRANÇA JUNIOR, P. Análise do uso e ocupação da Bacia do Córrego Pinhalzinho II utilizando geoindicadores, Umuarama - PR, 1970-2009. Dissertação (Mestrado em Geografia), Universidade Estadual de Maringá, Maringá, 2010.

FRANÇA JUNIOR, P.; VILLA, M. E. C. D. Análise macroscópica nas cabeceiras de drenagem da área urbana de Umuarama, região noroeste - Paraná/Brasil. Geografia Ensino \& Pesquisa, v. 17, n.1, 2013.

GOMES, P. M; MELO, C; VALE, V. S. Avaliação dos impactos ambientais em nascentes na cidade de Uberlândia - MG: análise macroscópica. Sociedade \& Natureza,Uberlândia, v.17, n.32, p.103- 120, 2005.

HABERLAND, N. T.; SILVA, F. C. B.; OLIVEIRA FILHO, P. C.; VITAL, C. M. S.; CAVALLIN, G. S. Análise da influência antrópica na qualidade da água do trecho urbano do rio das Antas na cidade de Irati, Paraná. Revista Tecnológica, v. 21. p.53-67, 2012.

HESPANHOL, K.M.H. Monitoramento e diagnóstico da qualidade da água do Ribeirão Morangueiro. Dissertação (Mestrado em Engenharia Urbana), Universidade Estadual de Maringá, Maringá, 2009.

IAP - Instituto Ambiental do Paraná. Monitoramento da qualidade das águas dos rios da região metropolitana de Curitiba, no período de 1992 a 2005. Curitiba, 2005.

IBGE - Instituto Brasileiro de Geografia e Estatística. Censo demográfico. Rio de Janeiro, 2010. 
KNAPIK, H. G. Reflexões sobre monitoramento, modelagem e calibração na gestão de recursos hídricos: estudo de caso da qualidade da água da Bacia do Alto Iguaçu. Dissertação (Mestrado em Engenharia de Recursos Hídricos e Ambiental), Universidade Federal do Paraná, Curitiba, 2009.

LEVIN, L.A., EKAU, W., GOODAY, A.J., JORISSEN, F., MIDDELBURG, J.J., NAQVI, S.W.A.,

MACÊDO, J. A. B. de. Introdução à química ambiental: química \& meio ambiente \& sociedade. 2 ed. Minas Gerais: CRQ, 2006.

NASCIMENTO, B.P.P.; MARCELINO, C.P.; OLIVEIRA, G.P.C.; AURORA, L.C.; CATARINACHO, R. L. Relatório de Aulas Práticas de Bioquímica I. Universidade Presbiteriana Mackenzie, São Paulo, 2009.

NEIRA, C., RABALAIS, N.N., ZHANG, J. Effects of natural and human-induced hypoxia on coastal benthos. Biogeosciences, v.6, p.2063-2098, 2009.

NUNES,J.A. Tratamento físico-químico de águas residuárias industriais. 6 ed. Editora Andrade, 2012.

ODUM, E.P. Fundamentos de Ecologia. 6a ed. Fundação Calouste Gulbenkian. 2001.

PARANÁ. SUREHMA - Superintendência dos Recursos Hídricos e Meio Ambiente. Portaria n 017 de 01 de Novembro de 1991. Legislação, Paraná, 1991.

RONQUIN, J. Degradação do córrego mimosa de Umuarama - Pr. Dissertação de Mestrado. Universidade Federal do Paraná, Curitiba, 2010.

PORTO, M. F. A.; PORTO, R. L. Gestão de bacias hidrográficas. Estudos Avançados. v.22, n.63, 2008.

SETTI, A. A.; LIMA, J. E. F. W.; CHAVES, A. G. M.; PEREIRA, I. C. Introdução ao gerenciamento de recursos hídricos. $2^{\mathrm{a}}$ ed. Brasília: Agência Nacional de Energia, Superintendência de Estudos e Informações Hidrológicas, 2001.

SCHNEIDER, R. M.; FREIRE, R.; COSSICH, E. S.; SOARES, P. F.; FREITAS, F. H.; TAVARES, C. R. G. Estudo da influência do uso e ocupação de solo na qualidade da água de dois córregos da Bacia hidrográfica do rio Pirapó.Acta Scientiarum. Technology, Maringá, v. 33, n. 3, p. 295-303, 2011.

TAKEDA, A. K.; MENDES, F. M.; MARIN, L. M. Avaliação da qualidade da água do lago Aratimbó no município de Umuarama/Pr. In: II Congresso Brasileiro de Gestão Ambiental, Londrina, Paraná, 2011. 
VILLA, M. E. C. D. Fontes de Poluição da Bacia do Córrego Pinhalzinho II em Umuarama - PR. Dissertação (Mestrado em Geografia), Universidade Estadual de Maringá, Maringá, 2010.

VILLA, M. E. C. D. Histórico de ocupação e os processos erosivos no município de Umuarama - PR. In: II Encontro Estadual de Geografia e Ensino e XX Semana de Geografia, Maringá, 2011.

VILLA, M. E. C. D Avaliação da carga suspensa total (CST) e de metais na bacia do córrego Pinhalzinho II no município de Umuarama - PR. Geografia Ensino \& Pesquisa, v. 15, n.2, 2011a.

VON SPERLING, M. Introdução à qualidade das águas e ao tratamento de esgotos. $3^{\text {a }}$ ed. Belo Horizonte: Departamento de Engenharia Sanitária e Ambiental. Universidade Federal de Minas Gerais, 2005.

WEINER, E. R.Applications of Environmental Aquatic Chemistry: a pratical guide. 2 ed. 2000.

WILKINS, P. M.; CAO1, Y.; HESKE, E. J.; LEVENGOOD, J. M. Influence of a forest preserve on aquatic macroinvertebrates, habitat quality, and water quality in an urban stream. Urban Ecosyst, v.18, p.989-1006, 2015. 